\title{
EFFECTS OF WATER DEFICIT AND SALT STRESS ON SOME PHOTOSYNTHESIS PARAMETERS IN WHEAT AND AEGILOPS COMOSA LINES
}

\section{Sándor Dulai i*, Réka Tarnai', Dóra Salamon1, István Molnár², András Vojtkó1, Jana Táborská1, Ammar Allem³, Márta Molnár-Láng ${ }^{2}$ \& Dóra Szopkó ${ }^{1}$}

${ }^{1}$ Eszterházy Károly University, Department of Botany and Plant Physiology, $H$ 3300 Eger, Leányka str. 6, Hungary; ${ }^{2}$ Hungarian Academy of Sciences, Centre for Agricultural Research, Agricultural Institute, H-2462 Martonvásár, Brunszvik str. 2, Hungary; Biological Doctoral School, St. Stephen University, H-2011 Gödöllö, Páter K. str. 6, Hungary; *E-mail: dulai.sandor@uni-eszterhazy.hu

\begin{abstract}
Photosynthetic responses of Aegilops comosa genotypes were compared to those of wheat Mv9kr1 and Chinese spring in order to verify whether $A e$. comosa TA2760 and MvGB1039 genotypes are potentially suitable gene sources for improving the drought and salt tolerance of bread wheat. Although there are some differences between the non-stressed plants and the measure of the decrease of the net-photosynthesis $\left(P_{\mathrm{N}}\right)$, it was strongly inhibited by water deficit. Salt stress had similar effect on $P_{\mathrm{N}}$ but at the highest $(300 \mathrm{mM}) \mathrm{NaCl}$ concentration $P_{\mathrm{N}}$ of the genotypes showed some activity. Severe drought induced a strong decrease in the effective quantum yield of PS II ( $\left.\phi_{\text {PSII }}\right)$ in the genotypes, while it was moderate in the case of salt treatment. Moreover, $\phi$ PSII was unaffected by the increase of $\mathrm{NaCl}$ concentration in wheat lines. Parallel with the decrease in $\phi_{\text {PSII }}$, the photoprotective mechanisms were enhanced in the wheat and wild wheat genotypes during water deficit. These results suggest that the Ae. comosa genotypes seem to respond to these stress factors with similar photosynthetic activity to the wheat lines. Thus, based on the above-mentioned facts, the examined $A$ e. comosa lines are not particularly good candidates for improving drought tolerance of wheat.
\end{abstract}

Keywords: wheat, Aegilops comosa, photosynthesis, water deficit, salt stress

\section{INTRODUCTION}

Abiotic environmental factors due to the forecasted effects of global climate change can considerably endanger the productivity of cultivated plants. An important problem is the rhapsodic rainfall 
pattern (Trenberth et al. 2007), which often results agricultural damages by drought and/or salt stress. Although drought is the most common abiotic stress factor (Araus et al. 2002) but also the agricultural lands are often affected by salt stress (Munns 2005). In field conditions, a positive relationship of photosynthetic capability and crop production has been well documented. At the same time, photosynthesis is particularly sensitive to drought and salinity (Ashraf and Harris 2013, Dulai et al. 2014, Szopkó et al. 2017a, Szopkó and Dulai 2018).

Under stress conditions the limitation of photosynthetic capacity takes place in two stages: (i) limitation associated with decreased stomatal conductance, known as stomatal limitation $\left(L_{\mathrm{s}}\right.$, Centritto et al. 2003, Dulai et al. 2014); (ii) limitation due to nonstomatal processes $\left(L_{\mathrm{ns}}\right)$ mainly at severe drought and higher salt concentrations or longer salt stress (James et al. 2002, Centritto et al. 2003, Munns et al. 2006, Szopkó et al. 2017b). Under moderate water deficit or in the first stage of salt stress, which also has osmotic effect, the reduction in net photosynthesis $\left(P_{\mathrm{N}}\right)$ mainly due to the stomatal closure (Chaves 1991; Medrano et al. 2002). In this case the $\mathrm{CO}_{2}$ diffusion into the leaves is also restricted resulting in a decrease in the intercellular $\mathrm{CO}_{2}$ concentration $\left(C_{\mathrm{i}}\right)$ (Cornic 2000) and $\mathrm{CO}_{2}$ carboxylation (Flexas et al. 2004). At the same time, the reduced stomatal conductance $\left(g_{s}\right)$ may contribute to maintaining water content through a decreased transpiration rate, which could be favourable for minimizing $\mathrm{Na}^{+}$transport towards the shoots (Tester and Davenport 2003). Thus, closed stomata have both positive and negative effects on photosynthesis (Szopkó et al. 2017b).

When the stress turns severe, photosynthesis is also limited by factors other than stomatal closure. The drought induced nonstomatal limitation of $P_{\mathrm{N}}$ may be caused by the restricted mesophyll conductance (Loreto et al. 2003) or by metabolic factors (Medrano et al. 1997, Centritto et al. 2003, Chaves et al. 2003). Similar to water deficit, salt stress also has many consequences for nonstoma-dependent processes as well. Salt-induced non-stomatal inhibition $\left(L_{\mathrm{ns}}\right)$ can be observed when the $\mathrm{CO}_{2}$ assimilation is disturbed by the presence of toxic ions. This limitation may be associated with limited Rubisco activity a reduced amount of Rubisco protein or week efficiency of PSII in the second stage of salt stress (Muranaka et al. 2002, Kalaji et al. 2011), when a high 
concentration of toxic $\mathrm{Na}^{+}$and $\mathrm{Cl}^{-}$ions evolves in the leaves (Munns and Tester 2008).

During drought and salt stress photosynthesis is often hindered by the secondary effect of disturbed water and ion homeostasis. The increasingly severe limitation of photosynthesis leads to the plant absorbing more light energy than that can be used by $\mathrm{CO}_{2}$ fixation (Smirnoff 1993). Although the excess light can be partially dissipated as heat, it has the potential to cause the over-reduction of the linear electron transport chain, leading to oxidative damage (Smirnoff 1993, Flexas et al. 2004). Under these circumstances the down-regulation of photosynthesis by non-radiative energy dissipation (Demmig-Adams et al. 1996) and/or photorespiration represent an efficient defence mechanism in $\mathrm{C}_{3}$ plants. Thus, the facility to maintain promising photosynthesis and consequently achieve adequate growth and production are based on these intensive protecting/regulating mechanisms.

Interspecific hybridization of wheat with wild relatives is an appropriate breeding strategy to improve the stress tolerance (Colmer et al. 2006, Schneider et al. 2008, Pradhan et al. 2012). Aegilops species are widely used as genetic resources in the breeding of bread wheat. These plants are native in the Mediterranean coastal areas characterised by hot, dry vegetation periods often with high salinity (Molnár et al. 2004, Dulai et al. 2006). Relating to this, Aegilops species might adapt to the unfavourable environmental conditions thus their ability to tolerate some abiotic stresses has already been partly described (Zaharieva et al. 2001, Molnár et al. 2004, Dulai et al. 2006).

However, the drought and salt tolerance of some Aegilops comosa genotypes is unclear. The aim of the present study was to clarify the drought and salt tolerance of the Ae. comosa TA2760 and MvGB1039 lines. For this purpose these plants were exposed to drought and salt stress and the photosynthetic responses of these genotypes were compared to those of wheat Mv9kr1 and Chinese spring. It is revealed that whether Ae. comosa TA2760 and MvGB1039 genotypes are potentially suitable gene sources for improving the drought and salt tolerance of bread wheat. 


\section{MATERIALS AND METHODS}

\section{Plant materials}

In our experiments Ae. comosa TA2760, MvGB1039, Mv9kr1 and Chinese spring wheat genotypes were investigated. The seeds of lines were provided by Márta Molnár-Láng and István Molnár, Agricultural Institute of the Hungarian Academy of Science (Martonvásár, Hungary). The seeds were germinated in laboratory conditions on filter paper moistened with distilled water than they were grown in half-strength modified Hoagland nutrient solution (Nagy and Galiba 1995) in $1500 \mathrm{ml}$ pots or were planted in soil (5 seeds/pot). Plants grow at $25 / 20^{\circ} \mathrm{C}$ in a growth chamber with a photosynthetic photon flux density of $200 \mu \mathrm{E} \mathrm{m}^{-2} \mathrm{~s}^{-1}$ and 14/10 hours of light/dark illumination. Salt stress was induced by applying 150 and $300 \mathrm{mM}$ concentration of $\mathrm{NaCl}$ (Sigma, St. Louis, USA) in seven-day cycles. After reaching the highest salt concentration, the salt was eliminated from the medium. Measurements were made before the treatment (5-week old plant), after each seven-day treatment and after two and seven days of regeneration without $\mathrm{NaCl}$. The watering of the Aegilops lines and wheat lines grown in soil was abolished after the age of 5 weeks. In the case of water-deficient plants, the measurements were performed on the 4th, 7th and 10th day of water shortage. The regeneration ability was investigated by the total humidification of the soil.

\section{Gas exchange measurements}

The $\mathrm{CO}_{2}$ assimilation of intact leaves was measured with an infrared gas analyser (GFS-3000FL, Walz, Effeltrich, Germany). The net assimilation rate $\left(P_{\mathrm{N}}\right)$ was calculated in the light-saturated state of photosynthesis $\left(1000 \mu \mathrm{mol} \mathrm{m}^{-2} \mathrm{~s}^{-1}\right)$ using the equations reported by von Caemmerer and Farquhar (1981). The gas exchange chamber parameters were $25^{\circ} \mathrm{C}, 20 \%$ relative humidity. The $\mathrm{CO}_{2}$ concentration of the reference air was $360 \mathrm{ppm}$.

\section{Chlorophyll fluorescence measurements}

The in vivo chlorophyll $a$ fluorescence was measured in darkadapted intact leaves using a dual channel P700 and chlorophyll fluorescence measuring system (Dual PAM-100, Walz, Effeltrich, Germany). The initial level of fluorescence $\left(F_{0}\right)$ was excited by a 
weak 460-nm light beam after 15 min dark adaptation. The maximal fluorescence level of the dark- $\left(F_{\mathrm{m}}\right)$ and light- $\left(F_{\mathrm{m}}{ }^{\prime}\right)$ adapted leaves were determined by applying saturating flashes (15000 $\left.\mu \mathrm{mol} \mathrm{m}{ }^{-2} \mathrm{~s}^{-1} \mathrm{PAR}\right)$ with $0.8 \mathrm{~s}$ duration. Photosynthesis was induced by continuous illumination of the leaf at $1000 \mu \mathrm{mol} \mathrm{m}{ }^{-2} \mathrm{~s}^{-1}$ (650 $\mathrm{nm}$, actinic light) for $10 \mathrm{~min}$. The fluorescence parameters were calculated as described by van Kooten and Snel (1990) on the basis of the following equations: maximal quantum yield of PSII, $F_{\mathrm{v}} / F_{\mathrm{m}}=\left(F_{\mathrm{m}}-F_{0}\right) / F_{\mathrm{m}}$; effective quantum yield of PSII, $\Phi_{\mathrm{PSII}}=\left(F_{\mathrm{m}}{ }^{\prime}-\right.$ $\left.F_{\mathrm{s}}\right) / \mathrm{F}_{\mathrm{m}}{ }^{\prime}$; non-photochemical quenching, $\mathrm{NPQ}=\left(F_{\mathrm{m}}-F_{\mathrm{m}}{ }^{\prime}\right) / F_{\mathrm{m}}{ }^{\prime}$.

\section{Statistical analysis}

Five measurements were performed on each genotypes and treatment for chlorophyll fluorescence and for $\mathrm{CO}_{2}$ gas exchange analyses. The results are presented as the means \pm standard deviations (SD) of five independent experiments. Differences between treatments or genotypes within each treatment were determined by means of Tukey's post hoc test $(p \leq 0.05)$ using the SPSS 16.0 software.

\section{RESULTS}

Water deprivation, similar to increase of salt concentration, resulted in a gradual decrease in stomatal conductance. In the water stressed lines almost total closure of the stomata was observed at the 10-day water stress while it was not fully complete at the highest salt concentration (data not shown). Although there are some differences between the non-stressed plants and the measure of the decrease of the $\mathrm{CO}_{2}$ assimilation rate, $P_{\mathrm{N}}$ was strongly inhibited by water deficit at the seventh day of treating (Figure 1A). When the drought stress was more severe (at the tenth day of the treatment) $P_{\mathrm{N}}$ was almost fully inhibited in all of the examined genotypes. Salt stress had similar effect on $P_{\mathrm{N}}$ but at the highest $(300 \mathrm{mM}) \mathrm{NaCl}$ concentration, $P_{\mathrm{N}}$ of the genotypes showed some residual activity. However, the measure of this inhibition was more or less proportional to that of the water-deficient plants. During the regeneration period $P_{\mathrm{N}}$ was restored swiftly for the drought treated plants: the recovery was complete on the second day of the relaxation period. In the case of salt stress the 
restoration was slower but also complete by the 7th day of the regeneration period.

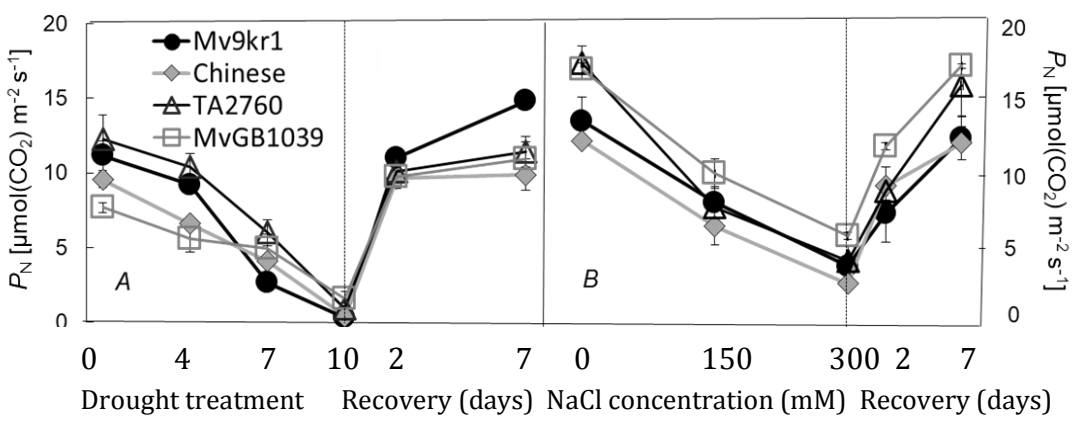

Figure 1. Effects of water deficit, $\mathrm{NaCl}$ concentration and recovery on net photosynthesis $\left(P_{\mathrm{N}}\right)$ in wheat (Mv9kr1, Chinese spring) cultivars and Aegilops comosa (TA2760, MvGB1039) genotypes.

Chlorophyll fluorescence measurements provide a fast and adequate method for analysing the functioning of the photosynthetic apparatus. Although there was a slight decrease in the optimal quantum yield of PS II $\left(F_{\mathrm{v}} / F_{\mathrm{m}}\right)$ by the second day of the regeneration period in the case of the salt treatment, both water and salt stresses did not result a significant decrease in this parameter in any plants (Figure 2C, F). In untreated plants and under mild (four day drought treatment and $150 \mathrm{mM} \mathrm{NaCl}$ ) stress conditions, $\phi_{\text {PSII }}$ was similar in the genotypes (Figure $2 A, D$ ). The severe drought induced a strong decrease in the effective quantum yield of PS II ( $\left.\phi_{\text {PSII }}\right)$ in the genotypes, while it was moderate in the case of salt treatment. Moreover, $\phi_{\text {PSII }}$ was unaffected by the increase of $\mathrm{NaCl}$ concentration in wheat Mv9kr1. Parallel with the decrease in $\phi_{\text {PSII }}$, the non-photochemical quenching (NPQ), reflecting the regulated heat dissipation, increased especially during the drought treatment, and slowly recovered to the original level after the stress treatments (Figure 2B). By contrast, NPQ showed a slight increase in Mv9kr1 and Chinese spring wheat cultivars during salt treatment. At the same time, this parameter rose sharply in Ae comosa TA2760 and MvGB1039 and did not recovered fully during the seven days relaxation period (Figure $2 E$ ). Thus, the 10-day water deprivation induced NPQ in all lines with very similar extent, but the increase of photo-protective 
mechanisms were detected only in Ae. comosa genotypes when salt stress was developed.

\section{DISCUSSION}

Under water deficit and/or salt stress, the stomata closure is a wellknown phenomenon (Molnár et al. 2004, Dulai et al. 2014, Szopkó et al. 2017b). The decrease in stomatal conductance $\left(g_{\mathrm{s}}\right)$ affects not only the regulation of water loss through the transpiration, but also inhibits the photosynthetic $\mathrm{CO}_{2}$ fixation by limiting $\mathrm{CO}_{2}$ diffusion into the leaves (Chaves 1991, Cornic 2000, Flexas and Medrano 2002). As mentioned above, the water deprivation caused an almost total closure of the stomata at the 10-day water stress (data not shown). In our experiments, the $\mathrm{CO}_{2}$ assimilation rate modified likewise as $g_{\mathrm{s}}: P_{\mathrm{N}}$ values were substantially decreased not only in wheat but also in wild wheat lines. Although the better tolerance of several Aegilops species to drought is well documented (Molnár et al. 2004, Dulai et al. 2006), these results indicate that drought tolerance of the examined wild wheat lines according to $\mathrm{CO}_{2}$ assimilation processes is similar to those in wheat genotypes. Thus, based on the overall photosynthetic capacity, the examined Ae. comosa lines are not particularly good candidates for improving drought tolerance of wheat.

Similar to drought, photosynthetic processes are also modified during salt stress (Szopkó et al. 2017b). Prior to the accumulation of toxic ions, salt treatment also causes osmotic stress, influencing the water status, stomatal conductance and net carbon fixation capacity of plants (Munns 2002, Munns and Tester 2008). $P_{\mathrm{N}}$ was a little bit higher in Ae. comosa MvGB1039 than this was in wheat lines at all levels of salt treatment $(\mathrm{P} \leq 0.05)$. Apart from this, it decreased considerably even at a moderate stress level in all lines.

These results show that the examined lines were not able to maintain their photosynthesis at a promising level during salt stress. Compared to the drought treatment, at $300 \mathrm{mM}$ salt concentration $P_{\mathrm{N}}$ of the genotypes showed a little bit higher activity than the 10-day water deprivation. This is probably due to the less strong closure of stomata. 


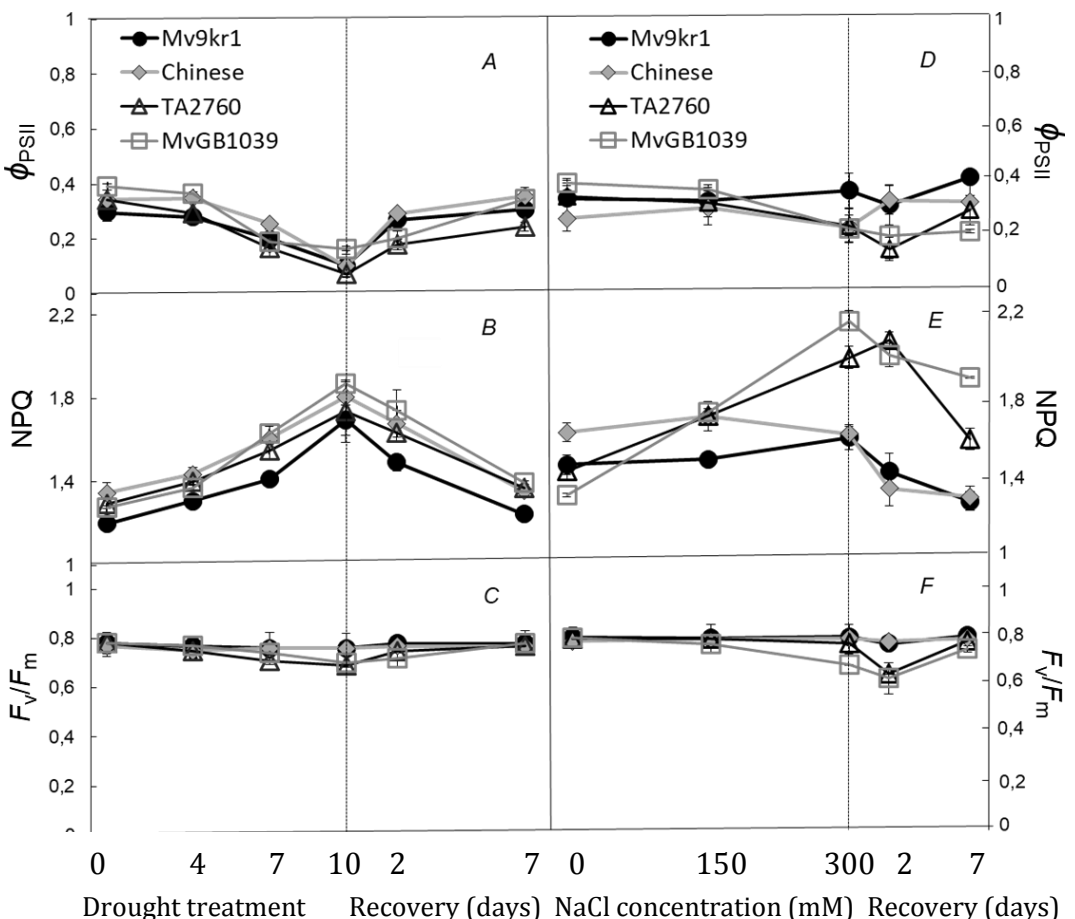

Figure 2. Effects of water deficit, $\mathrm{NaCl}$ concentration and recovery on effective quantum yield (A, D), non-photochemical quenching (B, E) and optimal quantum yield of PS II (C, F) in wheat (Mv9kr1, Chinese spring) cultivars and Aegilops comosa (TA2760, MvGB1039) genotypes.

When drought or salt stress become severe and $\mathrm{CO}_{2}$ assimilation is strongly inhibited, the role of non-stomatal factors in the limitation of photosynthesis usually becomes more pronounced (Brugnoli and Lauteri 1991, Qin et al. 2010). One of the nonstomatal factors affecting $\mathrm{CO}_{2}$ fixation during water deficit or salt stress is the inhibition of the photochemical and electron transport processes (Keck and Boyer 1974, Giardi et al. 1996, Szopkó et al. $2017 \mathrm{~b}$ ). At the same time, the contribution of these processes to the limitation of $P_{\mathrm{N}}$ usually depends on the duration/intensity of the treatment (Kalaji et al. 2011). In the present experiments, the optimal quantum yield $\left(F_{\mathrm{v}} / F_{\mathrm{m}}\right)$ were practically unaffected by the treatments. Consequently, our results show that the applied water deficit and salt treatment has only a marginal effect on the capacity of primary charge separation. Thus, no PSII damage observed, as 
also reported by previous studies (Ben et al.1987, Grieu et al. 1995, Dulai et al. 2006, 2014, Stiller et al. 2008, Szopkó et al. 2017b).

The different performance of effective quantum yield of PSII ( $\phi_{\text {PSII }}$ ), indicated that the electron transport processes were influenced distinctly by drought and salt stress in the given lines. Drought has significant effect on $\phi_{\text {PSII }}$ in all lines: the values of this parameter gradually decreased during the treatment indicating that electron transport processes were partly down-regulated in these genotypes. Parallel with the decrease of $\phi_{\text {PSII }}$ the photoprotective mechanisms were intensely accelerated in the wheat and wild wheat genotypes during water deficit, as indicated by the higher values of the non-photochemical quenching (NPQ). These processes compete with primary photochemistry for the absorbed excitation energy, leading to a decrease in $\phi_{\text {PSII }}$ (Genty et al. 1989) and an increase in non-radiative energy dissipation in the light-harvesting complexes (Horton and Ruban 2005, Chaves et al. $2009)$. In spite of the drought treatment, $\phi_{\text {PSII }}$ was less sensitive to the applied range of salt stress in most of the lines, and even in wheat genotypes, it has not decreased in parallel with the treatment. It seems unlikely that the down-regulation of the PSIIdriven electron transport is responsible for the limitation of photosynthesis, because the decrease in $\phi_{\text {PSII }}$ was relatively moderate and the relaxation of photosynthetic $\mathrm{CO}_{2}$ fixation in wheat genotypes was faster than the recovery of $\phi_{\text {PSII }}$. It has also been shown by several authors (Apostolova et al. 2006, Dulai et al. 2014, Szopkó et al. 2017b) that PSII is usually more sensitive to stress factors (drought, salt, heat, etc.) than PSI. Moreover, PSI activity may even be enhanced during salt stress (Sudhir et al. 2005). Consequently, there is a possibility that electrons may also follow a cyclic route, around the PSI and known as cyclic electron flow (CEF), which generate $\triangle \mathrm{pH}$ across the thylakoid membranes leading to the formation of ATP but not NADPH, thus preventing the over-reduction of the acceptor side of PSI. Consequently, CEF helps to prevent the subsequent oxidative damage when carbon fixation is limited by water deficit or salt stress (Golding and Johnson 2003, Dulai et al. 2014, Szopkó et al. 2017b). Based on the higher values of NPQ in all lines under severe drought and in Aegilops genotypes under severe salt stress might make it possible that CEF may help to prevent the over-reduction of the electron 
transport chain and subsequent oxidative damage (Dulai et al. 2014, Szopkó et al. 2017b).

In conclusion, the results proved that the examined Aegilops comosa lines were not able to maintain their photosynthesis at a promising activity under drought and salt stress. These lines seem to respond to these stress factors with similar photosynthetic activity to the wheat lines. Thus, based on the above-mentioned facts, the examined Ae. comosa lines are not particularly good candidates for improving drought and/or salt tolerance of wheat.

Acknowledgement - The first author's research was supported by the grant EFOP-3.6.1-16-2016-00001 ("Complex improvement of research capacities and services at Eszterházy Károly University"). Sándor Dulai is personally grateful to TAMOP 4.2.2A-11/1/KONV-2012-0008 project.

\section{REFERENCES}

Apostolova, E.L., Dobrikova, A.G., Ivanova, P.I. Petkanchin, I.B. \& TAneva, S.G. (2006). Relationship between the organization of the PSII supercomplex and the functions of the photosynthetic apparatus. Journal of Photochemistry and Photobiology B. 83: 114-122.

https://doi.org/10.1016/j.jphotobiol.2005.12.012

Araus, J.L., Slafer, G.A., Reynolds, M.P. \& Royo, C. (2002). Plant breeding and water relations in C3 cereals: what should we breed for? Annals of Botany 89: 925940. https://doi.org/10.1093/aob/mcf049

AshraF, M. \& HARRIS, P.J.C. (2013). Photosynthesis under stressful environments: An overview. Photosynthetica 51: 163-190.

http://dx.doi.org/10.1007/s11099-013-0021-6

Ben, G.Y., Osmond, C. \& Sharkey, T. (1987). Effects of water stress on in vivo photosynthetic biochemistry (maximum photosynthesis quantum yield and $77 \mathrm{~K}$ fluorescence). In: BigGins J. (ed.): Progress in Photosynthesis Research. Vol. V. Martinus-Nijhoff Publisher, Dordrecht, pp. 157-160.

BRUGNOLI, E. \& LAUTERI. M. (1991). Effects of salinity on stomatal conductance, photosynthetic capacity, and carbon isotope discrimination of salt-tolerant (Gossypium hirsutum L.) and salt-sensitive (Phaseolus vulgaris L.) $\mathrm{C}_{3}$ nonhalophytes. Plant Physiology 95: 628-635.

https://doi.org/10.1104/pp.95.2.628

Centritto, M., Loreto, F. \& Chartzoulakis, K. (2003). The use of low [ $\left.\mathrm{CO}_{2}\right]$ to estimate diffusional and non-diffusional limitations of photosynthetic capacity of salt-stressed olive saplings. Plant Cell and Environment 26: 585-594. https://doi.org/10.1046/j.1365-3040.2003.00993.x

ChAves, M.M. (1991). Effects of water deficits on carbon assimilation. Journal of Experimental Botany 42: 1-16. https://doi.org/10.1093/jxb/42.1.1

Chaves, M.M., Flexas, J. \& Pinheiro, C. (2009). Photosynthesis under drought and salt stress: regulation mechanisms from whole plant to cell. Annals of Botany 103: 551-560. http://dx.doi.org/10.1093/aob/mcn125 
Chaves, M.M., Maroco, J.P. \& Pereira. J.S. (2003). Understanding plant responses to drought - from genes to whole plant. Functional Plant Biology 30: 239-264. http://dx.doi.org/10.1071/FP02076

ColmeR, T.D., Flowers, T.J. \& MunNS, R. (2006). Use of wild relatives to improve salt tolerance in wheat. Journal of Experimental Botany 57: 1059-1078. https://doi.org/10.1093/jxb/erj124

CoRnIC, G. (2000). Drought stress inhibits photosynthesis by decreased stomatal aperture - not by affecting ATP synthesis. Trends in Biochemical Sciences 5: 187-188. https://doi.org/10.1016/S1360-1385(00)01625-3

Demmig-Adams, B., Adams, III W.W., BARKer, D.H., Logan, B.A., Bowling, D.R. \& VERHOEVEN A.S. (1996). Using chlorophyll fluorescence to assess the fraction of absorbed light allocated to thermal dissipation of excess excitation. Physiologia Plantarum 98: 253-264. https://doi.org/10.1034/j.1399-3054.1996.980206.x

Dulai S., Molnár I., Szopkó D., Darkó, E., VojtKó, A., SAsS-Gyarmati, A. \& Molnár-Láng, M. (2014). Wheat-Aegilops biuncialis amphiploids have efficient photosynthesis and biomass production during osmotic stress. Journal of Plant Physiolgy 171: 509-517. https://doi.org/10.1016/j.jplph.2013.11.015

Dulai, S., Molnár, I., Prónay, J., CSERnÁK, Á., TARnai, R. \& Molnár-LánG, M. (2006). Effects of drought on photosynthetic parameters and heat stability of PSII in wheat and in Aegilops species originating from dry habitats. Acta Biologica Szegediensis 50: 11-17.

Flexas, J., Bota, J., Loreto, F,. Cornic, G. \& Sharkey, Td. (2004). Diffusive and metabolic limitations to photosynthesis under drought and salinity in $\mathrm{C}_{3}$ plants. Plant Biology 6: 269-279. https://doi.org/10.1055/s-2004-820867

FleXas, J. \& MEdrano, H. (2002). Drought-inhibition of photosynthesis in $\mathrm{C}_{3}$ plants: stomatal and non-stomatal limitations revisited. Annals of Botany 89: 183-189. https://doi.org/10.1093/aob/mcf027

GentY, B., BRIANTAIS, J.M. \& BAKER, N.R. (1989). The relationship between the quantum yield of photosynthetic electron transport and quenching of chlorophyll fluorescence. Biochimica et Biophysica Acta (BBA) - General Subjects 990: 87-92. http://dx.doi.org/10.1016/S0304-4165(89)80016-9

Giardi, M.T., Cona, A., Gieken, B., Kucera, T., MasojíDeK, T. \& Mattoo, A.K. (1996). Long-term drought stress induces structural and functional reorganization of photosystem II. Planta 199: 118-125.

Golding, A.J. \& Johnson, G.N. (2003). Down-regulation of linear and activation of cyclic electron transport during drought. Planta 218: 107-114. https://doi.org/10.1007/s00425-003-1077-5

Grieu, P., Rubin, C. \& GuCKerT, A. (1995). Effect of drought on photosynthesis in Trifolium repens: maintenance of photosystem II efficiency and of measured photosynthesis. Plant Physiology and Biochemistry 33: 19-24.

Horton, P. \& Ruban, A. (2005). Molecular design of the photosystem II lightharvesting antenna: photosynthesis and photoprotection. Journal of Experimental Botany 56: 365-373. http://dx.doi.org/10.1093/jxb/eri023

James R.A., Von Caemmerer S., Condon A.G., Munns, R. \& Von Caemmerer, S. (2002). Genetic variation in tolerance to the osmotic stress component of salinity stress in durum wheat. Functional Plant Biology 35: 111-123.

https://doi.org/10.1071/FP07234 
Kalaji, H.M., Govindjee, Bosa, K., Koscielniak, J. \& ZuK-Golaszewska, K. (2011). Effects of salt stress on photosystem II efficiency and $\mathrm{CO}_{2}$ assimilation of two Syrian barley landraces. Environmental and Experimental Botany 73: 64-72.

https://doi.org/10.1016/j.envexpbot.2010.10.009

KECK, R. \& BOYER, J.S. (1974). Chloroplast response to low leaf water potentials. III. Differing inhibition of electron transport and photophosphorylation. Plant Physiology 53: 474-479. https://doi.org/10.1104/pp.53.3.474

Loreto, F., Centritto, M. \& Chartzoulakis, K. (2003). Photosynthetic limitations in olive cultivars with different sensitivity to salt stress. Plant Cell and Environment 26: 595-601. https://doi.org/10.1046/j.1365-3040.2003.00994.x

Medrano, H., Escalona, J.M., Bota, J., Gulías, J. \& Flexas, J. (2002). Regulation of photosynthesis of $\mathrm{C}_{3}$ plants in response to progressive drought: stomatal conductance as a reference parameter. Annals of Botany 89: 895-905. https://doi.org/10.1093/aob/mcf079

Medrano, H., Parry, M.A.J., Socias, X. \& LaWlor, D.W. (1997). Long term water stress inactivates Rubisco in subterranean clover. Annals of Applied Biology 131: 491-501. https://doi.org/10.1111/j.1744-7348.1997.tb05176.x

Molnár, I., GÁspár, L., SÁrvári, É., Dulai, S., Hoffmann, B., MolnÁr-LÁng, M. \& Galiba, G. (2004). Physiological and morphological responses to water stress is Aegilops biuncialis and Triticum aestivum genotypes with differing tolerance to drought. Functional Plant Biology 31: 1149-1159. https://doi.org/10.1071/FP03143

Munns, R. (2002). Comparative physiology of salt and water stress. Plant Cell and Environment 25: 239-250. https://doi.org/10.1046/j.0016-8025.2001.00808.x

MunNs, R. (2005). Genes and salt tolerance: bringing them together. New Phytologist 167: 645-663. https://doi.org/10.1111/j.1469-8137.2005.01487.x

Munns, R., JAMES, R.A. \& LÄUCHLI, A. (2006). Approaches to increasing the salt tolerance of wheat and other cereals. Journal of Experimental Botany 57: 10251043. https://doi.org/10.1093/jxb/erj100

Munns, R. \& Tester, M. (2008). Mechanisms of salinity tolerance. Annual Review of Plant Biology 59: 651-681. https://doi.org/10.1146/annurev.arplant.59.032607.092911

MuranaKa, S., SHImizU, K. \& Kato, M. (2002). Ionic and osmotic effects of salinity on single-leaf photosynthesis in two wheat cultivars with different drought tolerance. Photosynthetica 40: 201-207. https://doi.org/10.1023/A:1021337522431

NAGY, Z. \& GALIBA, G. (1995). Drought and salt tolerance are not necessarily linked: a study on wheat varieties differing in drought resistance under consecutive water and salinity stresses. Journal of Plant Physiology 145: 168-174. https://doi.org/10.1016/S0176-1617(11)81865-1

Pradhan, G.P., Prasad, P.V.V., FritZ, A.K., Kirkham, M.B. \& Gill, B.S. (2012). Response of Aegilops species to drought stress during reproductive stages of development. Functional Plant Biology 39: 51-59. https://doi.org/10.1071/FP11171

Qin, J., Dong W.Y., He K.N., Yu, Y. Tan, G.D., Han, L., DonG, M., Zhang, Y.Y., Zhang, D., LI, Z.A. \& WANG, Z.L. (2010). NaCl salinity induced changes in water status, ion 
contents and photosynthetic properties of Shepherdia argentea (Pursh) Nutt. seedlings. Plant, Soil and Environment 56: 325-332.

https://doi.org/10.17221/209/2009-PSE

Schneider, A., Molnár, I. \& MolnÁR-LÁng, M. (2008). Utilisation of Aegilops (goatgrass) species to widen the genetic diversity of cultivated wheat. Euphytica 163: 1-19. https://doi.org/10.1007/s10681-007-9624-y

SmiRnoff, N. (1993). The role of active oxygen in response of plants to water deficit and desiccation. New Phytologist 125: 27-58.

https://doi.org/10.1111/j.1469-8137.1993.tb03863.x

Stiller, I., Dulai, S., Kondrák, M., Tarnai, R., Szabó, L., Toldi, O. \& Bánfalvi, Z. (2008). Effects of drought on water content and photosynthetic parameters in potato plants expressing the trehalose-6-phosphate synthase gene of Saccharomyces cerevisiae. Planta 227: 299-308. https://doi.org/10.1007/s00425-007-0617-9

Sudhir, P., Pogoryelov, D., Kovács, L. Garab, G. \& Murthy, S.D.S. (2005). The effects of salt stress on photosynthetic electron transport and thylakoid membrane proteins in the cyanobacterium Spirulina platensis. Journal of Biochemistry Molecular Biology 38: 481-485. https://doi.org/10.5483/BMBRep.2005.38.4.481

Szopkó, D., Darkó, É., Molnár, I., Kruppa, K., Háló, B., VojtKó, A., MolnáR-LÁnG, M. \& Dulai, S. (2017b). Photosynthetic responses of a wheat (Asakaze)-barley (Manas) 7H addition line to salt stress. Photosynthetica 55: 317-328. https://doi.org/10.1007/s11099-016-0241-7

SzopKó, D. \& DulaI, S. (2018). Effects of drought and salt preconditioning on the heat resistance of the photosynthetic apparatus. Acta Biologica Plantarum Agriensis 6: 90-107. https://doi.org/10.21406/abpa.2018.6.90

Szopkó, D., Molnár, I., Darkó, É., Molnár-LánG, M. \& Dulai, S. (2017a). PEG-mediated osmotic stress responses of wheat-barley addition lines. Acta Biologica Plantarum Agriensis 5(2): 3-22. https://doi.org/10.21406/abpa.2017.5.2.3

Tester, M. \& DAVEnPoRT, R. (2003). $\mathrm{Na}^{+}$tolerance and $\mathrm{Na}^{+}$transport in higher plants. Annals of Botany 91: 503-527. https://doi.org/10.1093/aob/mcg058

Trenberth, K.E., Smith, L., Qian, T., DAi, A. \& Fassulo, J. (2007). Estimates of the Global Water Budget and Its Annual Cycle Using Observational and Model Data. Journal of Hydrometeorology 8: 758-769. https://doi.org/10.1175/JHM600.1

VAN Kooten, O. \& SNEL, J.F.H. (1990). The use of chlorophyll fluorescence nomenclature in plant stress physiology. Photosynthesis Research 25: 147-150. https://doi.org/10.1007/BF00033156

Von CAemmerer, S. \& Farquhar, G.D. (1981). Some relationships between the biochemistry of photosynthesis and the gas exchange of leaves. Planta 153: 376-387. https://doi.org/10.1007/BF00384257

Zaharieva, M., Gaulin, E., Havaux, M., Acevedo, E. \& Monneveux, P. (2001). Drought and heat responses in the wild wheat relative Aegilops geniculata Roth: Potential interest for wheat improvement. Crop Science 41: 1321-1329. https://doi.org/10.2135/cropsci2001.4141321x

(submitted: 16.10.2019, accepted: 14.11.2019) 